\title{
Trends and Patterns in the Public Awareness of Palliative Care, Euthanasia, and End-of-Life Decisions in 3 Central European Countries Using Big Data Analysis From Google: Retrospective Analysis
}

Matthias Huemer ${ }^{1}$, MD; Daniela Jahn-Kuch ${ }^{1}$, MSc, MD; Guenter Hofmann ${ }^{1}$, MD; Elisabeth Andritsch ${ }^{2}$, MSc; Clemens Farkas $^{2}$, MSc; Walter Schaupp ${ }^{3}$, PhD, MD; Eva Katharina Masel ${ }^{4}$, MSc, PhD, MD; Philipp J Jost ${ }^{2,5}$, PhD, MD; Martin Pichler ${ }^{2}$, MSc, MD

\footnotetext{
${ }_{1}^{1}$ Division of Oncology with affiliated Unit of Palliative Medicine, Department of Internal Medicine, Medical University of Graz, Graz, Austria

${ }^{2}$ Division of Oncology, Department of Internal Medicine, Medical University of Graz, Graz, Austria

${ }^{3}$ Institute of Moral Theology, University of Graz, Graz, Austria

${ }^{4}$ Clinical Division of Palliative Care, Department of Medicine I and Comprehensive Cancer Center, Medical University of Vienna, Vienna, Austria

${ }^{5}$ Department of Internal Medicine III - Hematooncology, Technical University of Munich School of Medicine, Technical University of Munich, Munich, Germany
}

Corresponding Author:

Martin Pichler, MSc, MD

Division of Oncology

Department of Internal Medicine

Medical University of Graz

Auenbruggerplatz 15

Graz, 8036

Austria

Phone: 43316385 ext 30196

Fax: 4331638513355

Email: martin.pichler@medunigraz.at

\section{Abstract}

Background: End-of-life decisions, specifically the provision of euthanasia and assisted suicide services, challenge traditional medical and ethical principles. Austria and Germany have decided to liberalize their laws restricting assisted suicide, thus reigniting the debate about a meaningful framework in which the practice should be embedded. Evidence of the relevance of assisted suicide and euthanasia for the general population in Germany and Austria is limited.

Objective: The aim of this study is to examine whether the public awareness documented by search activities in the most frequently used search engine, Google, on the topics of palliative care, euthanasia, and advance health care directives changed with the implementation of palliative care services and new governmental regulations concerning end-of-life decisions.

Methods: We searched for policies, laws, and regulations promulgated or amended in Austria, Germany, and Switzerland between 2004 and 2020 and extracted data on the search volume for each search term topic from Google Trends as a surrogate of public awareness and interest. Annual averages were analyzed using the Joinpoint Regression Program.

Results: Important policy changes yielded significant changes in search trends for the investigated topics. The enactment of laws regulating advance health care directives coincided with a significant drop in the volume of searches for the topic of euthanasia in all 3 countries (Austria: $-24.48 \%, P=.02$; Germany: $-14.95 \%, P<.001$; Switzerland: $-11.75 \%, P=.049$ ). Interest in palliative care increased with the availability of care services and the implementation of laws and policies to promote palliative care (Austria: 22.69\%, $P=.01$; Germany: 14.39, $P<.001$; Switzerland: $17.59 \%, P<.001)$. The search trends for advance health care directives showed mixed results. While interest remained steady in Austria within the study period, it increased by $3.66 \%(P<.001)$ in Switzerland and decreased by $2.85 \%(P<.001)$ in Germany. 
Conclusions: Our results demonstrate that legal measures securing patients' autonomy at the end of life may lower the search activities for topics related to euthanasia and assisted suicide. Palliative care may be a meaningful way to raise awareness of the different options for end-of-life care and to guide patients in their decision-making process regarding the same.

(J Med Internet Res 2021;23(9):e28635) doi: 10.2196/28635

\section{KEYWORDS}

Google Trends; end-of-life decisions; assisted suicide; euthanasia; palliative care; health care policy

\section{Introduction}

\section{Background}

How and to what extent a person may wish to be cared for when terminally ill and shortly before death should depend, without a doubt, solely on the expressed will of the concerned individual. Freedom of choice also includes the personal right to choose death over life [1]. In the case of advance health care directives, the right to a nontreatment decision and the consensual withdrawal of potentially curative treatments are protected by regulating acts in most Western countries [2]. Furthermore, suicide is not considered a crime in such places [2]. However, there is an ongoing debate on the extent to which a second person should assist a person in willingly dying [3]. Legal regulations concerning euthanasia and assisted suicide vary considerably among European countries. Although the Netherlands, Luxembourg, and Belgium allow euthanasia and assisted suicide under specific circumstances, Switzerland has more liberal legislation concerning assisted suicide but not euthanasia. Other countries in Europe strictly prohibit a death that involves a second person [2].

Principally, assisted suicide is not prohibited in Germany, as suicide per se is not considered a crime, but its commercial practice was restricted in 2015 [2]. On the other hand, Austria considers assisted suicide a crime per se and prohibits its practice entirely [2]. However, in 2020, the debate about end-of-life decisions was reignited in Germany and Austria after the constitutional courts in both countries declared the restriction of assisted suicide unconstitutional [4,5]. Both countries are currently in the process of liberalizing their legal regulations concerning this topic. However, voluntary death on demand remains prohibited in both countries $[4,5]$.

Palliative care is often considered an alternative and sometimes even contradictory to the active termination of a patient's life upon voluntary request [6]. The traditional aim of palliative care is to improve the quality of life of a severely ill person and to neither shorten nor unnecessarily prolong that life [7]. Hence, the European Association of Palliative Care (EAPC) dissociated itself from implementing euthanasia and assisted suicide in the context of palliative care in a recently published white paper [6]. Furthermore, the preventive effect of palliative care on the desire to hasten death and the request for euthanasia or assisted suicide has been repeatedly proposed but never confirmed $[8,9]$. It is more likely that palliative care may act as a filter for patients to differentiate between those who seek euthanasia and assisted suicide because of intrinsic reasons and those who have reactive suicidal thoughts because of severe temporary suffering $[8,10]$. The desire to die may be either a true conviction of euthanasia being the only acceptable option for the patient or a way to express suffering without the explicit wish to hasten death actively [10]. Suffering could be alleviated through palliative care, potentially leading to a lower desire to die in some patients [11]. However, it seems that palliative care does not prevent the request for euthanasia in patients who are already truly convinced to commit assisted suicide or euthanasia [8]. Hence, patients expressing a desire to die should be referred to palliative care to explore the underlying reasons resulting in a desire to hasten death before granting a request for assisted suicide or euthanasia [8-11].

Surveys among the general public in Germany and Austria show an increasing acceptance of euthanasia and assisted suicide [12-17]. However, these surveys often reflect only a general opinion toward the topic and rarely ask specifically about the demand for such options [12-17]. Usually, hypothetical scenarios of terminally ill persons are presented, and the participants are asked if euthanasia or assisted suicide is an appropriate option in a particular case [12-15]. In addition, some of the studies carry a particular risk of selection bias because of the topic's controversial nature [12,14]. People who are unwilling to participate because of their fundamental beliefs may be underrepresented. Furthermore, proportionally high participation of ideological supporters of euthanasia and assisted suicide may influence the outcome through a self-selection bias in these voluntary surveys [14].

A novel approach for estimating public interests, awareness, and behavior is the analysis of big data obtained from internet search engines such as Google, Yahoo!, and Bing [18]. Recorded Google search volumes are publicly available in anonymized form on the Google Trends platform [19]. The data have already been used to measure public interest in cancer screening [20] and trend changes in the public awareness of palliative care after the implementation of new governmental policies [21] or the death of a celebrity [22]. Google Trends was also used in a variety of other medical and health-related disciplines [23]. It was used to predict and track infectious diseases such as influenza [24] and Lyme disease [25] with comparable accuracy to traditional methods and represents a valuable epidemiological tool.

Compared with traditional surveys that assess opinions, a Google Trends analysis is a useful tool for estimating information needs. Such trends serve as a proxy for the demand for health care services, information needs, and curiosity about health-related topics [23]. A survey across the European Union on internet use found that $58.71 \%(15,598 / 26,566)$ of the respondents used the internet to obtain health-related information [26]. Of those who tried to find specific information about medical treatments and procedures, $76.5 \%$ (2724/3561) conducted searches for themselves, and $30.3 \%$ (1079/3561) had done so for a family 
member [26]. A total of 40.51\% (1119/2762) of those who rated their health as bad used the internet to obtain health-related information [26]. Hence, it is clear that the internet is an important source of information for Europeans, and search volumes represent the subjects of interest of a vast number of European Union citizens.

\section{Objective}

In Germany and Austria, no data about the demand for euthanasia or assisted suicide are available to date, as no register or comparable data acquisition is possible because of the restriction and prohibition of the practices, respectively. Therefore, in this study, we hypothesize that internet search behavior might provide a novel approach to gaining essential insights into the general population's needs and interests concerning palliative care, euthanasia, and end-of-life decisions. This study further aims to assess the influence of expanding care services and established governmental health care policies in both countries on the search behavior for each topic.

In addition, we chose Switzerland as a comparator as it is a (partly) German-speaking country and has already established practices for assisted suicide.

\section{Methods}

\section{Data Collection}

Google Trends data are available from January 2004 onward [19]. Therefore, we searched for relevant governmental policies, enacted or revised laws, and publicized health care strategies that emerged between January 2004 and December 2020 in each country (Germany, Austria, and Switzerland).

Every 6 years (starting in 2007), the EAPC publishes the EAPC Atlas of Palliative Care in Europe [27-29]. The report reviews the current status and availability of palliative care services for every European country. The available services per 100,000 citizens were obtained from each report to assess the development of palliative care over time.

Google gathers data on every search query performed on its search engine. The summarized data are publicly available in anonymous form on the Google Trends webpage [19]. Up to 5 search terms or topics can be simultaneously entered on the page. In contrast to search terms, search topics summarize several interrelated search terms and represent interest in a given topic more accurately. In addition, 4 filters can be applied: region, time, category, and search type. The output is the relative volume of queries for the search term or topic of interest to the total volume of queries in the selected region and period. The result is then scaled on a range of $0-100$. Repeated search queries of a single user within a short time are not recorded so as to prevent intentional influence and enhance data quality [18].
In our study, we used three search term topics: palliative care plus euthanasia plus advance health care directive. All 3 terms were entered in the German language. The search topic euthanasia summarizes queries regarding assisted suicide and voluntary euthanasia. On January 25, 2021, we downloaded the data on the monthly relative search volume from January 2004 to December 2020 for Germany, Austria, and Switzerland. We used all categories and web search as additional filters. After downloading the data, we calculated the annual mean for each search topic and performed a trend analysis using the Joinpoint Regression Program [30]. Finally, we compared the trends in relative search volumes and the significant turning points (joinpoints) to the implementation or revision of government policy changes.

\section{Data Analysis}

The Joinpoint Regression Program allows the analysis of trends over time and identifies apparent changes or turning points in the direction of a trend [30]. We calculated the yearly average from the monthly relative search volumes for each keyword and region and performed a joinpoint analysis using a log-linear Poisson regression model. Model selection was based on the Bayesian information criterion. This approach has already been established in previous studies investigating the impact of governmental policies on public awareness and internet search behavior [31].

\section{Results}

\section{Legal Developments After 2004}

Table 1 shows a timeline of public health strategies and passed or revised laws for each country. Before 2004, palliative care services were already established in all 3 countries but were still in their infancy [32]. At the turn of the millennium, the first health care policies concerning the care of terminally ill patients were implemented [33-35]. After that, in all 3 countries, continuous advancements were made concerning the financing, education, and implementation strategies for palliative care. Legal regulations about end-of-life decisions and advance health care declarations were first passed in 2006 in Austria [36], followed by Germany in 2009 [37] and Switzerland in 2013 [38]. The provision granted patients a higher degree of autonomy in their health care decisions. The legislature in Austria further discriminates between legally binding and nonbinding advance health care directives [36]. The latter aims to communicate the patient's preferences for end-of-life care and allows the treating physician to reconsider a previously dismissed medical treatment or procedure depending on the situation, whereas the legally binding form provides a detailed and definite description of nontreatment decisions in predefined health conditions [36]. 
Table 1. Timeline of public health strategies and laws passed or revised after 2004 for Austria, Germany, and Switzerland.

\begin{tabular}{|c|c|c|c|}
\hline Year & Austria & Germany & Switzerland \\
\hline 2004 & $\begin{array}{l}\text { Public health care strategy: concept of graded hospice } \\
\text { and palliative care in Austria }\end{array}$ & Register of health care proxies & $-^{\mathrm{a}}$ \\
\hline 2006 & $\begin{array}{l}\text { Law: advance health care directive (legally binding and } \\
\text { nonbinding) }\end{array}$ & - & $\begin{array}{l}\text { The Swiss Academy of Medical Sciences } \\
\text { issues medical ethics guidelines for pal- } \\
\text { liative care }\end{array}$ \\
\hline 2007 & Law: health care proxy & $\begin{array}{l}\text { Law: specialized ambulatory palliative } \\
\text { care as a mandatory insurance benefit }\end{array}$ & - \\
\hline 2008 & - & - & Novelty: adult guardianship law \\
\hline 2009 & - & Law: advance health care directive & $\begin{array}{l}\text { National strategy: Palliative Care 2010- } \\
2012\end{array}$ \\
\hline 2012 & - & - & $\begin{array}{l}\text { National strategy: Palliative Care 2013- } \\
2015\end{array}$ \\
\hline 2013 & - & - & Law: advance health care directive \\
\hline 2015 & $\begin{array}{l}\text { A parliamentary commission of inquiry: "Dignity at the } \\
\text { end of life" with } 51 \text { resolutions for financing, promoting, } \\
\text { and establishing palliative care services }\end{array}$ & $\begin{array}{l}\text { Law: hospice and palliative medicine } \\
\text { statute; prohibition of services for as- } \\
\text { sisted suicide }\end{array}$ & $\begin{array}{l}\text { Establishment: National Platform for } \\
\text { Palliative Care }\end{array}$ \\
\hline 2018 & Novelty: adult guardianship law & - & - \\
\hline 2020 & $\begin{array}{l}\text { Constitutional court rescinds the prohibition of assisted } \\
\text { suicide }\end{array}$ & $\begin{array}{l}\text { Constitutional court rescinds the prohi- } \\
\text { bition of services for assisted suicide }\end{array}$ & - \\
\hline
\end{tabular}

${ }^{\mathrm{a}}$ No public health strategies and laws were passed or revised during this year.

Assisted suicide has been exempt from punishment since 1918 in Switzerland and 1751 in Germany, whereas it was explicitly prohibited in Austria in 1934 [39]. However, Germany restricted the commercial use of assisted suicide in 2015, meaning that neither a business-like organization nor a nonprofit institution could offer assistance in dying [4]. In 2020, the constitutional courts in Germany and Austria revised their restrictive laws and declared them unjust, paving the way for the legal practice of assisted suicide [4,5]. In both countries, legislators are currently forming meaningful regulations to prevent the duplicitous use of this practice. Voluntary euthanasia is still prohibited in all 3 countries [39].

\section{Development of Palliative Care Services}

The results of the regulatory changes and public health strategies are regularly reported in the EAPC Atlas of Palliative Care in Europe [27-29]. In summary, the public accessibility of stationary, ambulatory, and voluntary services increased considerably in all 3 countries. Palliative care services per 100,000 citizens doubled from 2007 to 2019 from 0.6 to 2.2 in Austria, 0.4 to 1.1 in Germany, and 0.5 to 1.1 in Switzerland [27-29]. The results are summarized in Table 2.

Table 2. Development of palliative care services between 2007 and 2019 for each country.

\begin{tabular}{llll}
\hline Country & \multicolumn{2}{l}{ Palliative care services per 100,000 citizens } & 2019 \\
& 2007 & 2013 & 2.2 \\
\hline Austria & 0.6 & 1.4 & 1.1 \\
Germany & 0.4 & 0.7 & 1.1 \\
Switzerland & 0.5 & 0.8 & \\
\hline
\end{tabular}

\section{Internet Search Behavior}

\section{General Findings}

The search trends for each keyword and country are shown in Figure 1. In general, the search activity for palliative care increased over the studied period, whereas interest in euthanasia decreased in all 3 countries. The topic of advance health care directives showed mixed results. The greatest change in the average annual relative search volume for palliative care between 2004 and 2020 occurred in Switzerland, where there was an increase of $13.76 \%$ (95\% CI 1.43-27.60; $P=.03$ ), followed by Germany with 9.15\% (95\% CI 6.12-12.27; $P<.001)$ and then Austria (7.8\%, 95\% CI 2.96-12.88; $P<.001)$. 
Figure 1. Trends in relative search volume for each country. Vertical dashed lines indicate passed or revised public health strategies or laws concerning palliative care, euthanasia, or advance health care directives. The colored frames indicate the years of significant trend changes according to the joinpoint analysis. RSV: relative search volume.

A Relative search volume in Austria

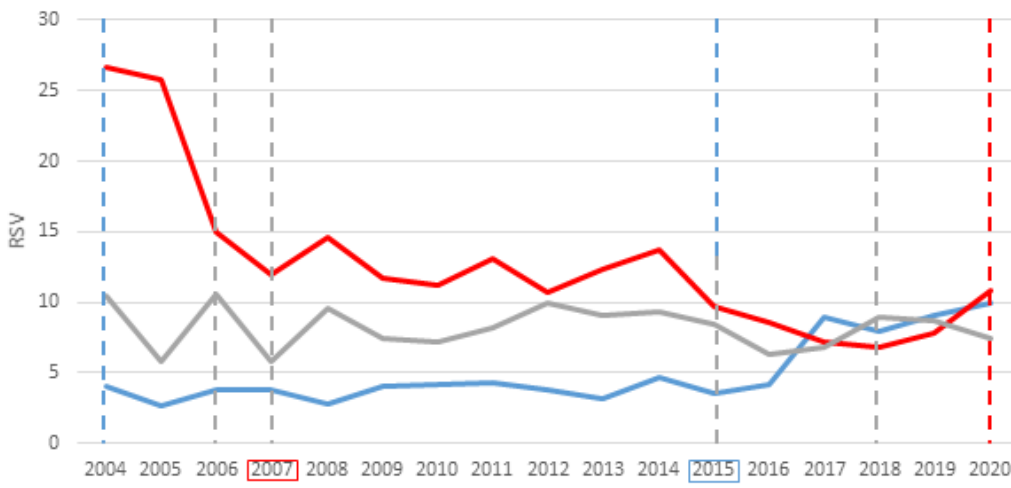

Year

- Palliative care Euthanæia _-Advanced health car edr rective

B

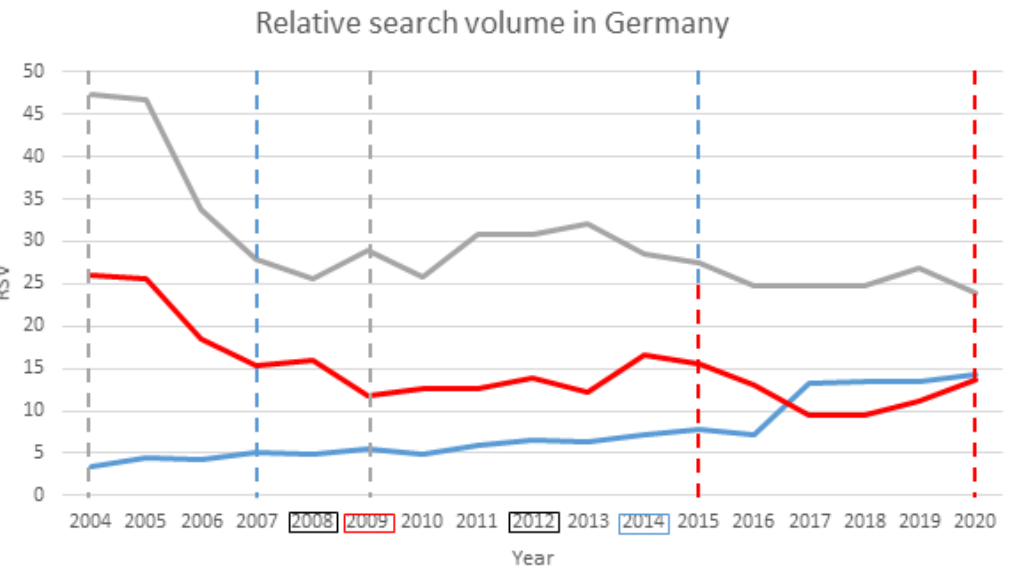

Palliative care Euthanasia

C

Relative search volume in Switzerland

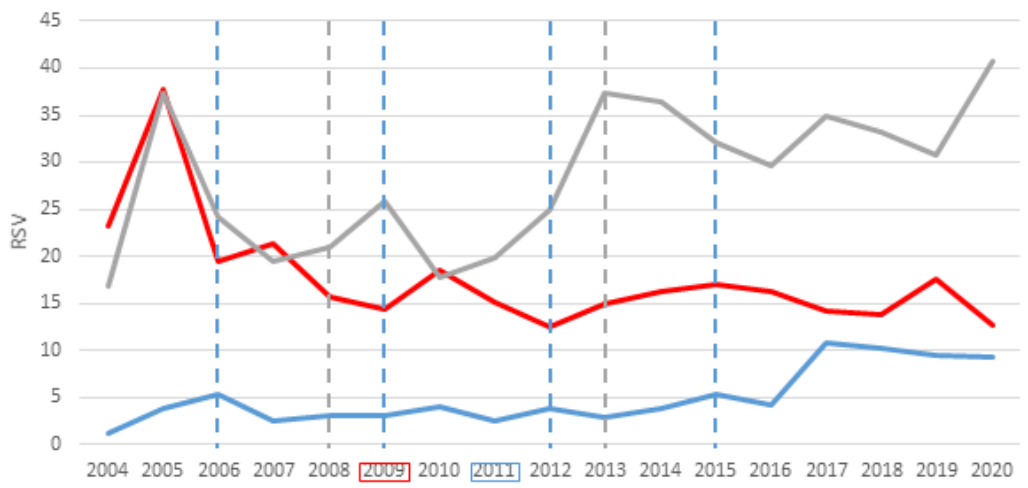

Year

- Palliative care Euthanasia Advanced health car e directive

Interest in euthanasia decreased in all 3 countries between 2004 and 2020. However, we found a significant decrease only in Switzerland, with a change of $4.15 \%(95 \%$ CI -8.09 to -0.04 ; $P=.047)$ per year. For Germany and Austria, the relative search volume decreased by $4.13 \%(95 \% \mathrm{CI}-11.09$ to $3.38 ; P=.27)$ and $6.07 \%(95 \% \mathrm{CI}-12.78$ to $1.15 ; P=.10)$, respectively.
We found different results for the search behavior of advance health care directives in each country. Although the relative search volume remained at a consistent level in Austria, with an insignificant decrease of $0.16 \%$ (95\% CI -2.27 to 1.99 ; $P=.87$ ) across the study period, the volume significantly decreased by $2.85 \%(95 \%$ CI -4.32 to $-1.35 ; P<.001)$ in 
Germany and significantly increased by $3.66 \%$ (95\% CI $1.18-6.21 ; P<.001)$ in Switzerland.

\section{Austria}

The joinpoint analysis revealed significant trend changes in the search terms' trajectories, which are presented in Table 3. We recorded joinpoints for the interest topics of palliative care and euthanasia; however, none were found for advance health care directives. In 2006 and 2007, two new laws regulating advance health care directives and the appointment of health care proxies were enacted by the Austrian parliament. Following these enactments, the relative search volume for euthanasia dropped by $24.48 \%$ (95\% CI -39.20 to -6.19$)$. Afterward, 2 periods with an insignificant but continuous reduction occurred, although this trend was more prominent from 2014 to 2018 than from 2007 to 2014 (Table 3). Toward the end of the study period in 2020, we observed a positive trend, although the difference was not significant (Table 3). In 2015, the parliamentary commission of inquiry regarding dignity at the end of life adopted 51 resolutions to promote and fund palliative care, followed by a $22.69 \%$ (95\% CI 7.05-40.61; $P=.01)$ increase in the search interest in palliative care. Until then, there had been a positive but small slope (Table 3 ). Although it fluctuated over the whole study period, the search trend for advance health care directives remained at a steady level without significant trend changes between 2004 and 2020 (Table 3).

Table 3. Trend periods and annual percentage of change in the search volume for each term in Austria.

\begin{tabular}{|c|c|c|}
\hline Trend periods & Annual change (95\% CI; \%) & $P$ value \\
\hline \multicolumn{3}{|l|}{ Palliative care } \\
\hline $2004-2015$ & $1.65(-2.44$ to 5.91$)$ & .40 \\
\hline $2015-2020$ & $22.69(7.05$ to 40.61$)$ & .01 \\
\hline \multicolumn{3}{|l|}{ Euthanasia } \\
\hline 2004-2007 & $-24.48(-39.20$ to -6.19$)$ & .02 \\
\hline $2007-2014$ & $-0.42(-7.46$ to 7.15$)$ & .89 \\
\hline 2014-2018 & $-15.02(-31.59$ to 5.55$)$ & .12 \\
\hline $2018-2020$ & $29.74(-15.91$ to 100.17$)$ & .19 \\
\hline \multicolumn{3}{|c|}{ Advance health care directive } \\
\hline 2004-2020 & $-0.16(-2.27$ to 1.99$)$ & .87 \\
\hline
\end{tabular}

\section{Germany}

The search trends in Austria and Germany were similar; however, the latter had joinpoints in all 3 keywords. The results are summarized in Table 3. With the legal regulation of advance health care directives in 2009, the relative search volume for euthanasia dropped by $14.39 \%$ (95\% CI -21.80 to -7.50 ; $P<.001)$. After a slight positive trend, a negative slope appeared in 2015 , followed by a positive trend in 2018 . However, none of these changes were significant (Table 4). Within the relative search volume trend for palliative care, one joinpoint was determined in 2014, dividing the overall period into 2 segments of significant positive slopes. Although in the first period the interest grew continuously by $6.12 \%$ (95\% CI 2.93-9.40; $P<.001)$, a sudden rise of $14.39 \%$ (95\% CI 7.06-22.23; $P<.001)$ appeared in 2014 after the enactment of a law regulating hospice and palliative care accessibility. Interestingly, the search trend for advance health care directives followed a pattern comparable with the trend for euthanasia, with a drop of $15.42 \%$ (95\% CI -22.03 to $-8.25 ; P<.001)$ in 2008 . Afterward, the search activity grew between 2008 and 2012 but became negative thereafter (Table 4). 
Table 4. Trend periods and annual percentage of change in the search term for each term in Germany.

\begin{tabular}{clc}
\hline Trend periods & Annual change $(95 \%$ CI; $\%)$ & $P$ value \\
\hline $\begin{array}{c}\text { Palliative care } \\
2004-2014 \\
2014-2020\end{array}$ & $6.12(2.93$ to 9.40$)$ & $<.001$ \\
Euthanasia & $14.39(7.06$ to 22.23$)$ & $<.001$ \\
$2004-2009$ & $-14.95(-21.80$ to -7.50$)$ & .001 \\
$2009-2015$ & $4.13(-4.26$ to 13.26$)$ & .28 \\
$2015-2018$ & $-16.83(-42.88$ to 21.08$)$ & .27 \\
$2018-2020$ & $24.97(-14.17$ to 81.95$)$ & .20 \\
Advance health care directive & & $<.001$ \\
$2004-2008$ & $-15.42(-22.03$ to -8.25$)$ & .39 \\
$2008-2012$ & $5.19(-7.49$ to 19.62$)$ & .01 \\
$2012-2020$ & $-3.30(-5.98$ to -0.55$)$ &
\end{tabular}

\section{Switzerland}

In Switzerland, similar trends in search activity, presented in Table 5, were found. The adult guardianship law was amended in 2008, and it included the regulation of advance health care directives. This amendment was followed by a decrease of $11.75 \%$ (95\% CI -22.09 to $-0.04 ; P=.049$ ) in the relative volume of searches for euthanasia between 2004 and 2009. In the following years, the trend remained stable and slightly negative (Table 5). However, this result is likely biased by the extraordinary peak in the relative search volume in 2005. At that time, the broad public debate about euthanasia and suicide tourism coincided with a higher search activity [40].

Table 5. Trend periods and annual percentage of change in the search volume for each term in Switzerland.

\begin{tabular}{lll}
\hline Trend periods & Annual change $(95 \%$ CI; \%) & $P$ value \\
\hline $\begin{array}{c}\text { Palliative care } \\
2004-2006\end{array}$ & $73.35(-21.41$ to 282.38$)$ & .15 \\
$2006-2011$ & $-9.44(-29.48$ to 16.30$)$ & .39 \\
$2011-2020$ & $17.59(9.40$ to 26.40$)$ & .001 \\
Euthanasia & $-11.75(-22.09$ to -0.04$)$ & .049 \\
$2004-2009$ & $-0.49(-4.15$ to 3.32$)$ & .78 \\
$2009-2020$ & & $<.001$ \\
Advance health care directive & & \\
$2004-2020$ & $3.66(1.18$ to 6.21$)$ &
\end{tabular}

Nevertheless, after 2009 (the calculated joinpoint), no likewise peak was observed, and the overall trend followed a negative slope (Table 5). For palliative care, the search activity increased significantly by $17.59 \%$ (95\% CI 9.40-26.40; $P<.001$ ) from 2011 onward after the government proposed its first national strategy for promoting the implementation of palliative care. Interest in advance health care directives increased significantly by $3.66 \%(95 \%$ CI $1.18-6.21 ; P<.001)$ across the study period.

\section{Discussion}

\section{Principal Findings}

Our study results show that between 2004 and 2020, substantial legal and public health efforts were made to promote patients' autonomy in regulating end-of-life decisions and develop palliative care services in Austria, Germany, and Switzerland, as summarized in Table 1. According to our analysis, a reduction in search activity for topics related to euthanasia ensued. At the same time, interest in palliative care in all 3 countries increased. Our results support previous findings regarding why individuals consider or eventually choose voluntary death. The fear of losing control over medical decisions and being helpless against a system capable of unnecessarily prolonging a life of suffering puts individuals under pressure to take action themselves [41]. Euthanasia, assisted suicide, and advance health care directives grant individuals a high level of autonomy and self-control, especially at the end of their life. Precise regulations for advance health care directives may have provided a viable alternative option to assisted suicide. For example, the provision of alternatives decreased interest in euthanasia, according to our results. Of note is the significant increase in the search interest in advance health care directives in Switzerland, even though assisted suicide is available. Specifically, we found significant trend changes that aligned with specific governmental actions. 
We found that public awareness of palliative care increased with the realization of public health strategies and the enactment of laws to regulate funding, education, accessibility, and insurance coverage related to palliative care. A previous study using Google Trends data from the United States showed similar results, with increased public awareness for palliative care from January 2005 to December 2015 [21]. The authors also suggest a correlation between this increase in search queries and changes in insurance providers' policies promoting advance care planning and the growth in nationwide palliative care service provision [21]. This result underlines the importance of government efforts to strengthen public awareness and promote access to palliative care services for those who need them. It is important to mention that interest in palliative care also increased in Switzerland, a country with established practices for assisted suicide. However, the government actions concerning palliative care did not align with the trend changes in the search activity for euthanasia, suggesting that there were other factors with a more significant impact on the decreased interest in assisted suicide and death on demand, such as legal regulations concerning the promotion of autonomy at the end of life. The embedment of advance health care directives and the legal appointment of health care proxies into a legal framework was followed by a significant drop in search queries for terms related to euthanasia and assisted suicide.

Before legal regulations were put in place, advance health care directives were a gray area and were theoretically not legally binding, allowing them to be overruled by caregivers and medical staff without facing consequences [42]. The formulation of a sound legal framework eliminated this uncertainty for patients and has potentially led to a higher sense of autonomy, which is in a complex relationship with perceived dignity and personal identity [10]. The desire to maintain a sense of control and autonomy also includes the desire to control different aspects of one's dying process but not necessarily wishing to hasten death actively [43]. However, situations threatening autonomy may be experienced as an undermining of one's dignity, evoking existential fears of patients that may produce a sense of urgency to take self-action [43]. On the other hand, promoting autonomy with the provision of advance care planning leads to higher emotional and mental well-being [44] and quality of life [45] of patients with progressive life-limiting diseases. It appears that the legal regulations of advance health care directives secured the wish to maintain control over the dying process and led to the decreased necessity of seeking information about other opportunities, such as traveling to other countries for assisted suicide.

The significant increase in popularity of search terms related to advance health care directives in Switzerland, the only studied country with established legal practices of assisted suicide, supports the hypothesis that they are a viable alternative option. However, this trend showed different results in the other 2 countries compared with that in Switzerland. At the beginning of the study period, in Germany, the high search volume might have resulted from a high degree of uncertainty about the legal options available, leading to increased search activity to obtain information about the requirements for advance health care directives. Formulating clear regulations could have led to a drop in the queries as it was easier to obtain precise details about such practices. In Austria, the search volume for advance health care directives did not change considerably during the study period. This raises the question of which factors may have contributed to this trend. Although the new legal framework provides clear definitions for legally binding directives and grants a high degree of self-determination through its binding character, Austrians face a cost barrier of up to $€ 500$ (US $\$ 584.50$ ) for the certifying notary [46]. This is approximately one-third of the average middle-class salary and hinders low-income Austrians from accessing this option [46]. In practice, patients use legally binding directives less frequently than nonlegally binding directives, which require neither notarial certification nor informed consent or discussion with a physician [47]. Therefore, patients may not seek as much information about how to arrange a legally binding directive or may discuss potentially confusing options primarily with their physicians.

Given the current developments in Germany and Austria, which tend to legalize assisted suicide practices, palliative care services could be involved in the decision-making process to find the best solution for each patient. Professional palliative caregivers are experienced in discussing sensitive topics such as end-of-life decisions and can inform patients about the different options in an evidence-based manner. Recent literature reviews have highlighted the benefits of early palliative care implementation in oncology, including an increase in the number of stipulated advance health care directives [48]. Therefore, palliative care may serve as a filter for patients with a genuinely intrinsic wish to hasten death actively and guide them in a meaningful and supportive way [8]. Evaluating the underlying reasoning, fears, and perhaps misunderstandings of individuals about end-of-life care is crucial in preventing the misuse of euthanasia and assisted suicide [49-52]. With the legalization of assisted suicide, it would be reasonable to simultaneously increase the accessibility of palliative care and extend its early integration into the treatment of terminally ill patients.

\section{Limitations}

Some limitations of this study need to be discussed. First, this is a correlative retrospective study, and hence, it does not allow for definite conclusions about causal relationships between the enactment of policies and the investigated search trends. However, we tried to minimize the potential bias by comparing the trends in 3 comparable countries and were able to show similar results, even in Switzerland, which has notably liberal regulations concerning the practice of assisted suicide.

Second, Google Trends does not provide absolute numbers and therefore lacks transparency to some extent. Researchers can rely only on the process description that Google publishes on its webpage concerning the handling of its data [19]. Of note are the preventive measures taken against bias by limiting the number of queries per user within a specific time. With this, active manipulation and repeated search queries (eg, during a literature search) did not influence the overall search volume and therefore represented the search activity within a region more accurately.

Third, we used search topics instead of definite search terms to limit the chances of choosing a less commonly used search term. 
However, this option may have also included nonspecific search terms. The most popular search terms are still included in the output of a trend query, and in our case, these queries predominantly showed specific terms related to the research question in this study. The output (in German) for each country and each search topic are presented in Tables S1-S3 in Multimedia Appendix 1.

Fourth, the trend changes might have been influenced by factors other than legal regulations and health care policies. For example, through the constant improvement of disease-specific and supportive therapies over the past two decades, the disease burden of many life-limiting diseases decreased while simultaneously focusing on enhancing patients' quality of life [53].

\section{Implications}

Our study provides novel and essential information about the demands and interests of the residents of Austria, Germany, and Switzerland concerning palliative care, euthanasia, assisted suicide, and end-of-life decisions. In particular, policy makers may use these findings to target potential weaknesses within current regulations (eg, the cost barrier for advance health care directives in Austria). Governmental promotion of the early implementation of palliative care into life-threatening disease trajectories may be another meaningful action. Experts in palliative care can sensitize patients to arranging advance health care directives, inform them about the different options at the end of life, and resolve misunderstandings.

\section{Conclusions}

Our study shows, for the first time, that governmental regulations, precise legal definitions, and broader access to advance health care directives might reduce interest in euthanasia, suggesting that loss of control is one of the predominant factors involved in the desire to hasten death. Early palliative care can guide patients through the necessary decision-making processes from the point of the diagnosis of a life-threatening disease to their death and provide advance care planning. After all, it is and has always been a core principle of palliative care to promote and value the autonomy of patients.

\section{Authors' Contributions}

MH contributed to the idea formulation, study design, data analysis and interpretation, and writing of the manuscript. DJK and GH contributed to the study design, data interpretation, and writing of the manuscript. EA, CF, WS, EKM, and PJJ contributed to the data interpretation and literature review. MP contributed to the data interpretation, study design, and language editing. All authors reviewed the final manuscript.

\section{Conflicts of Interest}

PJJ has had a consulting or advisory role, received honoraria, research funding, travel or accommodation expenses from Abbvie, Bayer, Boehringer, Novartis, Pfizer, Servier, Roche, Bristol Myers Squibb, and Celgene.

\section{Multimedia Appendix 1}

Most popular search terms.

[DOC File, 183 KB-Multimedia Appendix 1]

\section{References}

1. Horn R. The right to a self-determined death as expression of the right to freedom of personal development: the German Constitutional Court takes a clear stand on assisted suicide. J Med Ethics 2020 Jun;46(6):416-417. [doi: 10.1136/medethics-2020-106197] [Medline: 32220872]

2. Möller HJ. The ongoing discussion on termination of life on request. A review from a German/European perspective. Int J Psychiatry Clin Pract 2021 Mar;25(1):2-18. [doi: 10.1080/13651501.2020.1797097] [Medline: 32729770]

3. Kremeike K, Pralong A, Boström K, Bausewein C, Simon ST, Lindner R, Working Group on Desire to Die of the German Palliative Care Guideline. 'Desire to Die' in palliative care patients-legal framework and recommendations of the national evidence-based guideline on palliative care in Germany. Ann Palliat Med 2021 Mar;10(3):3594-3610 [FREE Full text] [doi: 10.21037/apm-20-381] [Medline: 33440974]

4. Hyde R. Germany overturns ban on assisted suicide. Lancet 2020 Mar 07;395(10226):774. [doi: 10.1016/S0140-6736(20)30533-X] [Medline: 32145781$]$

5. Es gilt das gesprochene Wort!. Verfassungsgerichtshof Österreich. URL: https://www.vfgh.gv.at/downloads/G 139. 2019 Verkuendung.pdf [accessed 2021-08-31]

6. Radbruch L, Leget C, Bahr P, Müller-Busch C, Ellershaw J, de Conno F, Board Members of EAPC. Euthanasia and physician-assisted suicide: a white paper from the European Association for Palliative Care. Palliat Med 2016 Feb;30(2):104-116. [doi: 10.1177/0269216315616524] [Medline: 26586603]

7. Sepúlveda C, Marlin A, Yoshida T, Ullrich A. Palliative care: the World Health Organization's global perspective. J Pain Symptom Manage 2002 Aug;24(2):91-96 [FREE Full text] [doi: 10.1016/s0885-3924(02)00440-2] [Medline: 12231124]

8. Dierickx S, Deliens L, Cohen J, Chambaere K. Involvement of palliative care in euthanasia practice in a context of legalized euthanasia: a population-based mortality follow-back study. Palliat Med 2018 Jan;32(1):114-122 [FREE Full text] [doi: 10.1177/0269216317727158] [Medline: 28849727] 
9. Gordijn B, Janssens R. The prevention of euthanasia through palliative care: new developments in The Netherlands. Patient Educ Couns 2000 Aug;41(1):35-46. [doi: 10.1016/s0738-3991(00)00113-0] [Medline: 10900365]

10. Rodríguez-Prat A, Monforte-Royo C, Porta-Sales J, Escribano X, Balaguer A. Patient perspectives of dignity, autonomy and control at the end of life: systematic review and meta-ethnography. PLoS One 2016 Mar 24;11(3):e0151435 [FREE Full text] [doi: 10.1371/journal.pone.0151435] [Medline: 27010323]

11. Lindner R, Foerster R, von Renteln-Kruse W. Physical distress and relationship problems: exploring the psychosocial and intrapsychic world of suicidal geriatric patients. Z Gerontol Geriatr 2014 Aug;47(6):502-507. [doi: 10.1007/s00391-013-0563-z] [Medline: 24202298]

12. Stolz E, Burkert N, Großschädl F, Rásky É, Stronegger WJ, Freidl W. Determinants of public attitudes towards euthanasia in adults and physician-assisted death in neonates in Austria: a national survey. PLoS One 2015 Apr 23;10(4):e0124320 [FREE Full text] [doi: 10.1371/journal.pone.0124320] [Medline: 25906265]

13. Stolz E, Großschädl F, Mayerl H, Rásky É, Freidl W. Determinants of acceptance of end-of-life interventions: a comparison between withdrawing life-prolonging treatment and euthanasia in Austria. BMC Med Ethics 2015 Dec 01;16(1):81 [FREE Full text] [doi: 10.1186/s12910-015-0076-y] [Medline: 26625908]

14. Stolz E, Mayerl H, Gasser-Steiner P, Freidl W. Attitudes towards assisted suicide and euthanasia among care-dependent older adults (50+) in Austria: the role of socio-demographics, religiosity, physical illness, psychological distress, and social isolation. BMC Med Ethics 2017 Dec 07;18(1):71 [FREE Full text] [doi: 10.1186/s12910-017-0233-6] [Medline: 29212490]

15. Stolz E, Mayerl H, Waxenegger A, Rásky É, Freidl W. Attitudes towards end-of-life decisions in case of long-term care dependency: a survey among the older population in Austria. J Med Ethics 2017 Jun;43(6):413-416. [doi: 10.1136/medethics-2016-103731] [Medline: 28235885]

16. Anneser J, Jox RJ, Thurn T, Borasio GD. Physician-assisted suicide, euthanasia and palliative sedation: attitudes and knowledge of medical students. GMS J Med Educ 2016 Feb 15;33(1):Doc11 [FREE Full text] [doi: 10.3205/zma001010] [Medline: 26958648]

17. Jahn-Kuch D, Domke A, Bitsche S, Stöger H, Avian A, Jeitler K, et al. End-of-life decision making by Austrian physicians - a cross-sectional study. BMC Palliat Care 2020 Jan 04;19(1):4 [FREE Full text] [doi: 10.1186/s12904-019-0509-3] [Medline: $\underline{31901225]}$

18. Nuti SV, Wayda B, Ranasinghe I, Wang S, Dreyer RP, Chen SI, et al. The use of google trends in health care research: a systematic review. PLoS One 2014 Oct 22;9(10):e109583 [FREE Full text] [doi: 10.1371/journal.pone.0109583] [Medline: 25337815]

19. Google Trends. URL: https://trends.google.com/trends/?geo=IN [accessed 2021-08-13]

20. Schootman M, Toor A, Cavazos-Rehg P, Jeffe DB, McQueen A, Eberth J, et al. The utility of Google Trends data to examine interest in cancer screening. BMJ Open 2015 Jun 08;5(6):e006678 [FREE Full text] [doi: 10.1136/bmjopen-2014-006678] [Medline: 26056120]

21. McLean S, Lennon P, Glare P. Internet search query analysis can be used to demonstrate the rapidly increasing public awareness of palliative care in the USA. BMJ Support Palliat Care 2019 Mar;9(1):40-44. [doi: 10.1136/bmjspcare-2016-001171] [Medline: 28130324]

22. Lane T, Ramadurai D, Simonetti J. Public awareness and perceptions of palliative and comfort care. Am J Med 2019 Feb;132(2):129-131. [doi: 10.1016/j.amjmed.2018.07.032] [Medline: 30076826]

23. Mavragani A, Ochoa G, Tsagarakis KP. Assessing the methods, tools, and statistical approaches in Google Trends research: systematic review. J Med Internet Res 2018 Nov 06;20(11):e270 [FREE Full text] [doi: 10.2196/jmir.9366] [Medline: $\underline{30401664]}$

24. Ginsberg J, Mohebbi MH, Patel RS, Brammer L, Smolinski MS, Brilliant L. Detecting influenza epidemics using search engine query data. Nature 2009 Feb 19;457(7232):1012-1014. [doi: 10.1038/nature07634] [Medline: 19020500]

25. Seifter A, Schwarzwalder A, Geis K, Aucott J. The utility of "Google Trends" for epidemiological research: Lyme disease as an example. Geospat Health 2010 May;4(2):135-137. [doi: 10.4081/gh.2010.195] [Medline: 20503183]

26. Flash Eurobarometer 404 (European citizens' digital health literacy). GESIS Data Archive. 2015. URL: https://search. gesis.org/research data/ZA5948 [accessed 2021-08-13]

27. Arias-Casais N, Garralda E, Rhee J, de Lima L, Pons J, Clark D, et al. EAPC Atlas of Palliative Care in Europe 2019. Vilvoorde: EAPC vzw Press; May 2019.

28. Centeno C, Clark D, Lynch T, Rocafort J, Flores L, Greenwood A, et al. EAPC Atlas of Palliative Care in Europe. Houston: IAHPC Press; 2007.

29. Centeno C, Rocafort J, Lynch C, Clark D, Donea O. EAPC Atlas of Palliative Care in Europe 2013. Milano: European Association for Palliative Care; Jun 2013.

30. Kim HJ, Fay MP, Feuer EJ, Midthune DN. Permutation tests for joinpoint regression with applications to cancer rates. Stat Med 2000 Feb 15;19(3):335-351. [doi: 10.1002/(sici)1097-0258(20000215)19:3<335::aid-sim336>3.0.co;2-z] [Medline: 10649300]

31. Lin R, Cheng Y, Jiang Y. Exploring public awareness of overwork prevention with big data from Google Trends: retrospective analysis. J Med Internet Res 2020 Jun 26;22(6):e18181 [FREE Full text] [doi: 10.2196/18181] [Medline: 32589160] 
32. Centeno C, Clark D, Lynch T, Racafort J, Praill D, De Lima L, EAPC Task Force. Facts and indicators on palliative care development in 52 countries of the WHO European region: results of an EAPC Task Force. Palliat Med 2007 Sep;21(6):463-471. [doi: 10.1177/0269216307081942] [Medline: 17846085]

33. Lang A. The good death and the institutionalisation of dying: an interpretive analysis of the Austrian discourse. Soc Sci Med 2020 Jan;245:112671. [doi: 10.1016/j.socscimed.2019.112671] [Medline: 31734481]

34. Melching H. [New legal regulations for palliative care with implications for politics and practice]. Bundesgesundheitsblatt Gesundheitsforschung Gesundheitsschutz 2017 Jan;60(1):4-10. [doi: 10.1007/s00103-016-2480-y] [Medline: 27995269]

35. Framework for palliative care in Switzerland. Federal Office of Public Health FOPH, Swiss Conference of the Cantonal Ministers of Public Health. URL: https://www.bag.admin.ch/bag/de/home/strategie-und-politik/ nationale-gesundheitsstrategien/strategie-palliative-care.html [accessed 2021-08-13]

36. Körtner HJ. [Patient advance directives in Austria--ethical discussions]. Bull Soc Sci Med Grand Duche Luxemb 2008(3):279-287. [Medline: $\underline{\text { 19069726] }}$

37. Evans N, Bausewein C, Meñaca A, Andrew EV, Higginson IJ, Harding R, project PRISMA. A critical review of advance directives in Germany: attitudes, use and healthcare professionals' compliance. Patient Educ Couns 2012 Jun;87(3):277-288. [doi: 10.1016/j.pec.2011.10.004] [Medline: 22115975]

38. Haesen S, Shaw D. Directing citizens to create advance directives. Swiss Med Wkly 2018 May 16;148:w14628 [FREE Full text] [doi: 10.4414/smw.2018.14628] [Medline: 29767827]

39. Grosse C, Grosse A. Assisted suicide: models of legal regulation in selected European countries and the case law of the European Court of Human Rights. Med Sci Law 2015 Oct;55(4):246-258. [doi: 10.1177/0025802414540636] [Medline: 25143341]

40. Shondell Miller D, Gonzalez C. When death is the destination: the business of death tourism - despite legal and social implications. Int J Culture Tourism Hosp Res 2013 Aug 02;7(3):293-306. [doi: 10.1108/ijcthr-05-2012-0042]

41. Chapple A, Ziebland S, McPherson A, Herxheimer A. What people close to death say about euthanasia and assisted suicide: a qualitative study. J Med Ethics 2006 Dec;32(12):706-710 [FRE Full text] [doi: 10.1136/jme.2006.015883] [Medline: 17145910]

42. Wiesing U, Jox RJ, Hessler H, Borasio GD. A new law on advance directives in Germany. J Med Ethics 2010 Dec;36(12):779-783. [doi: 10.1136/jme.2010.036376] [Medline: 21112938]

43. Monforte-Royo C, Villavicencio-Chávez C, Tomás-Sábado J, Mahtani-Chugani V, Balaguer A. What lies behind the wish to hasten death? A systematic review and meta-ethnography from the perspective of patients. PLoS One 2012;7(5):e37117 [FREE Full text] [doi: 10.1371/journal.pone.0037117] [Medline: 22606338]

44. Dyar S, Lesperance M, Shannon R, Sloan J, Colon-Otero G. A nurse practitioner directed intervention improves the quality of life of patients with metastatic cancer: results of a randomized pilot study. J Palliat Med 2012 Aug;15(8):890-895 [FREE Full text] [doi: 10.1089/jpm.2012.0014] [Medline: 22559906]

45. Bakitas M, Lyons KD, Hegel MT, Balan S, Brokaw FC, Seville J, et al. Effects of a palliative care intervention on clinical outcomes in patients with advanced cancer: the Project ENABLE II randomized controlled trial. J Am Med Assoc 2009 Aug 19;302(7):741-749 [FREE Full text] [doi: 10.1001/jama.2009.1198] [Medline: 19690306]

46. Schaden E, Herczeg P, Hacker S, Schopper A, Krenn CG. The role of advance directives in end-of-life decisions in Austria: survey of intensive care physicians. BMC Med Ethics 2010 Oct 21;11:19 [FREE Full text] [doi: 10.1186/1472-6939-11-19] [Medline: 20964852]

47. Köstenberger M, Diegelmann S, Terlutter R, Bidmon S, Neuwersch S, Likar R. Advance directives in Austrian intensive care units: an analysis of prevalence and barriers. Resusc Plus 2020 Jun 28;3:100014 [FREE Full text] [doi: 10.1016/j.resplu.2020.100014] [Medline: 34223298]

48. Hui D, Hannon BL, Zimmermann C, Bruera E. Improving patient and caregiver outcomes in oncology: team-based, timely, and targeted palliative care. CA Cancer J Clin 2018 Sep;68(5):356-376 [FREE Full text] [doi: 10.3322/caac.21490] [Medline: 30277572]

49. Breitbart W, Pessin H, Rosenfeld B, Applebaum AJ, Lichtenthal WG, Li Y, et al. Individual meaning-centered psychotherapy for the treatment of psychological and existential distress: a randomized controlled trial in patients with advanced cancer. Cancer 2018 Aug 01;124(15):3231-3239 [ [FREE Full text] [doi: 10.1002/cncr.31539] [Medline: 29757459]

50. Breitbart W, Rosenfeld B, Gibson C, Pessin H, Poppito S, Nelson C, et al. Meaning-centered group psychotherapy for patients with advanced cancer: a pilot randomized controlled trial. Psychooncology 2010 Jan;19(1):21-28 [FREE Full text] [doi: 10.1002/pon.1556] [Medline: 19274623]

51. Breitbart W, Rosenfeld B, Pessin H, Applebaum A, Kulikowski JS, Lichtenthal WG. Meaning-centered group psychotherapy: an effective intervention for improving psychological well-being in patients with advanced cancer. J Clin Oncol 2015 Mar 01;33(7):749-754 [FREE Full text] [doi: 10.1200/JCO.2014.57.2198] [Medline: 25646186]

52. Julião M, Oliveira F, Nunes B, Carneiro AV, Barbosa A. Effect of dignity therapy on end-of-life psychological distress in terminally ill Portuguese patients: a randomized controlled trial. Palliat Support Care 2017 Dec;15(6):628-637. [doi: $\underline{10.1017 / \text { S1478951516001140] [Medline: 28166861] }}$ 
53. Santos JV, Souza J, Valente J, Alonso V, Ramalho A, Viana J, et al. The state of health in the European Union (EU-28) in 2017: an analysis of the burden of diseases and injuries. Eur J Public Health 2020 Jun 01;30(3):573-578. [doi: 10.1093/eurpub/ckz203] [Medline: $\underline{31821479}$ ]

\section{Abbreviations}

EAPC: European Association of Palliative Care

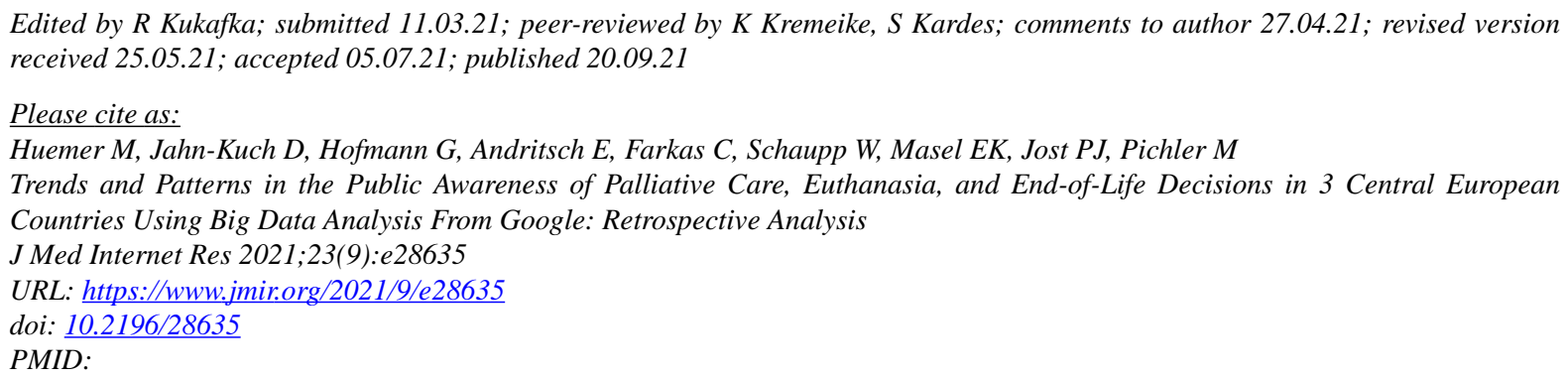

(CMatthias Huemer, Daniela Jahn-Kuch, Guenter Hofmann, Elisabeth Andritsch, Clemens Farkas, Walter Schaupp, Eva Katharina Masel, Philipp J Jost, Martin Pichler. Originally published in the Journal of Medical Internet Research (https://www.jmir.org), 20.09.2021. This is an open-access article distributed under the terms of the Creative Commons Attribution License (https://creativecommons.org/licenses/by/4.0/), which permits unrestricted use, distribution, and reproduction in any medium, provided the original work, first published in the Journal of Medical Internet Research, is properly cited. The complete bibliographic information, a link to the original publication on https://www.jmir.org/, as well as this copyright and license information must be included. 